\title{
Effects of Personality Traits on Member Loyalty to Online Communities: Investigation from the Views of Relationship Proneness, Relational Benefits, and Relationship Quality
}

\author{
Ying-Wei Shih ${ }^{1,}$, Hsien-Chang Huang ${ }^{1}$, Tzung-I Tang ${ }^{2}$ \\ ${ }^{1}$ Department of Information Management, National Changhua University of Education, Changhua, Taiwan \\ ${ }^{2}$ Department of Management Information Systems, National Chengchi University, Taipei, Taiwan
}

Email address:

ywshih@im.ncue.edu.tw (Ying-Wei Shih)

${ }^{*}$ Corresponding author

\section{To cite this article:}

Ying-Wei Shih, Hsien-Chang Huang, Tzung-I Tang. Effects of Personality Traits on Member Loyalty to Online Communities: Investigation from the Views of Relationship Proneness, Relational Benefits, and Relationship Quality. International Journal of Science, Technology and Society. Vol. 4, No. 3, 2016, pp. 41-47. doi: 10.11648/j.ijsts.20160403.11

Received: April 7, 2016; Accepted: April 18, 2016; Published: May 7, 2016

\begin{abstract}
The ubiquity of the Internet has accelerated the growth of online communities. The administrators of such communities must consider not only how to recruit new members, but also how to encourage loyalty among existing members. Based on previous works, the present study explored the relationships among personality traits, relationship proneness, relational benefits, relationship quality, and loyalty in the context of online communities. The research sample comprised 599 online community members. The results indicated the positive effects of social affiliation and involvement on relationship proneness, of relationship proneness on relational benefits, of relational benefits on satisfaction and relationship commitment, of satisfaction on relationship commitment and loyalty, and of relationship commitment on loyalty.
\end{abstract}

Keywords: Online Communities, Personality Traits, Relationship Proneness, Relational Benefits, Relationship Quality, Loyalty

\section{Introduction}

Advancements in information and communication technology have facilitated the development of many successful Internet-based platforms, including online communities. Numerous types of online community exist, each with various features and goals [1]. In such virtual environments, people can interact and exchange information with others anonymously to fulfill their social or task needs [2]. In online communities, interpersonal interactions are not constrained by time and space; thus, such communities have grown into a large virtual society, second only to the real-world society, and participating in online communities has become an important part of people's modern life.

The rapid growth of online communities has created a new challenge for online community operators: they must explore not only how to attract new members, but also how to convert existing members into loyal ones, who would willingly share information or perform profitable actions (e.g., purchasing) and increase the value of the community [3].

Relationship marketing literature indicates that relationship quality is the key to loyalty, and relationship quality can be measured in terms of satisfaction, trust, commitment, and service quality [4]. In addition, relational benefits and relationship proneness have crucial roles in developing loyalty. Relational benefits originate from successful relationships between customers and service providers [5]. Such successful relationships are built on the service provider's marketing strategy and the customer's proneness to engaging in such relationships [6]. Furthermore, relational benefits and relationship proneness are determinants of relationship quality $[7,8]$.

The effects of the aforementioned variables on loyalty have been empirically confirmed in the service industry. The persistence of these effects in online communities remains unclear. The purpose of this study was to apply theoretical models concerning relational benefits and relationship proneness, including those proposed by Hennig-Thurau et al. [5], Odekerken-Schröder et al. [7], and Vázquez-Carrasco and 
Foxall [8], to the investigation of factors in building loyalty in online communities. The following research questions were addressed:

1. Which dimensions of relationship quality affect loyalty in online communities?

2. How do relational benefits and relationship proneness affect relationship quality in online communities?

3. Which personality traits are associated with relationship proneness?

\section{Theoretical Background}

Hennig-Thurau et al. [5] proposed that relational benefits influence relationship quality, which in turn influences relationship marketing outcomes. In their study, relational benefits were divided into confidence benefits, social benefits, and special treatment benefits, and relationship quality included satisfaction and commitment. Furthermore, relationship marketing outcomes were examined through customer loyalty and word of mouth. The authors reported the positive effects of both satisfaction and commitment on customer loyalty and word of mouth, of satisfaction on commitment, of confidence benefit on satisfaction and customer loyalty, of social benefit on commitment and customer loyalty, and of special treatment benefit on commitment.

Odekerken-Schröder et al. [7] proposed a conceptual model of retailer-consumer relationships. The model was divided into three submodels: Submodel 1 was associated with relationship marketing tactics, Submodel 2 with personality traits, and Submodel 3 with relationship outcomes. The authors further examined the relationships between the three submodels and reported that among the four proposed types of personality trait, product category involvement had a significant impact on relationship proneness, whereas the remaining three traits - social affiliation, social recognition, and shopping enjoyment-did not.

Vázquez-Carrasco and Foxall [8] proposed a model considering the relationships between customer personality traits (i.e., need for variety and social affiliation), relationship proneness, relational benefits, satisfaction, and loyalty. The results of a test demonstrated that both of the personality traits had a significant impact on relationship proneness and that relational benefits had a critical intermediary role between relationship proneness and satisfaction.

\section{Research Hypotheses}

The present study explored factors that build loyalty in online communities. The research model, shown in Fig. 1, was based on the studies of Hennig-Thurau et al. [5], Odekerken-Schröder et al. [7], and Vázquez-Carrasco and Foxall [8]. Because the focus was on online community members, rather than retail consumers, the personality trait of shopping enjoyment proposed by Odekerken-Schröder et al. [7] was considered inapplicable. The present study adopted the three remaining personality trait types, in addition to the trait of need for variety proposed by Vázquez-Carrasco and Foxall [8], and explored the effect of the personality traits on relationship proneness. Although Odekerken-Schröder et al. [7] confirmed that involvement has a positive effect on relationship proneness, the present study incorporated the effect of social recognition on relationship proneness - which was unconfirmed and hypothesized in their study on the basis of the literature - into the research model. In addition, Vázquez-Carrasco and Foxall [8] reported that need for variety and social affiliation had a negative effect and a positive effect, respectively, on relationship proneness. Consequently, the present study proposed the following hypotheses:

H1: Social affiliation has a positive impact on relationship proneness

H2: Social recognition has a positive impact on relationship proneness

H3: Involvement has a positive impact on relationship proneness

H4: Need for variety has a negative impact on relationship proneness

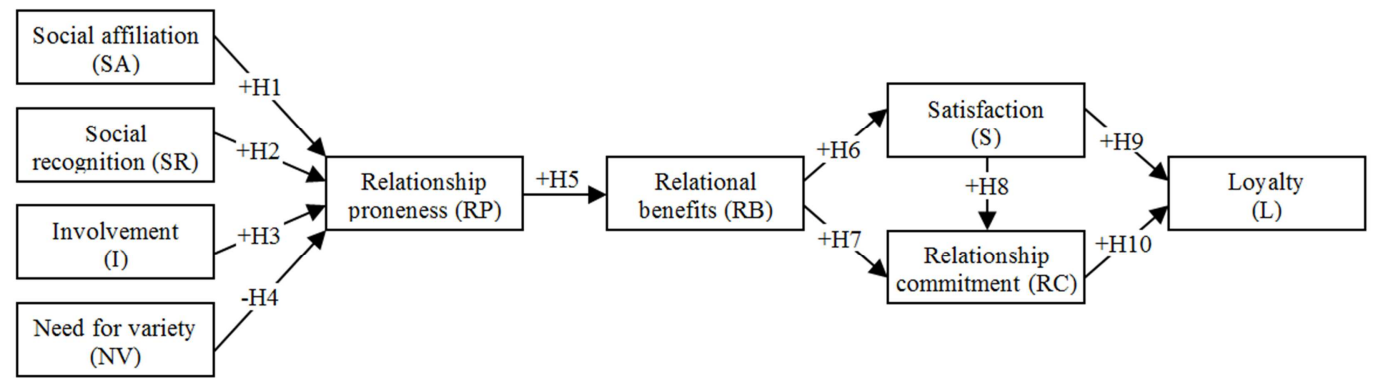

Figure 1. Research model.

Hennig-Thurau et al. [5] identified three types of relational benefits: confidence benefits, social benefits, and special treatment benefits. Considering the characteristics of online communities, the present study used the first two types but adopted a unitary construct strategy to represent relational benefits. Vázquez-Carrasco and Foxall [8] showed that relationship proneness positively influences relational benefits, which in turn positively influences satisfaction. Adamson et al. [9] investigated relational benefits in the context of small banks in Hong Kong and reported a positive relationship between relational benefits and customer commitment. In addition, Park and Kim [10] confirmed a positive relationship 
between relational benefits and customer commitment among users of online stores and online ticketing systems. On the basis of these findings, the present study proposed the following hypotheses:

H5: Relationship proneness has a positive impact on relational benefits

H6: Relational benefits have a positive impact on satisfaction

H7: Relational benefits have a positive impact on relationship commitment

According to Hennig-Thurau et al. [5], the relationship quality construct comprises satisfaction and relationship commitment; both of these subconstructs positively influence loyalty, and satisfaction positively influences relationship commitment. Caruana [11] supported the viewpoint that customer satisfaction influences loyalty. Furthermore, Abdul-Muhmin [12] reported that relationship satisfaction has a positive impact on relationship commitment, and Selnes [13] and Macintosh and Lockshin [14] have revealed that customer satisfaction and commitment have positive impacts on loyalty. Therefore, the present study proposed the following hypotheses:

H8: Satisfaction has a positive impact on relationship commitment

H9: Satisfaction has a positive impact on loyalty

H10: Relationship commitment has a positive impact on loyalty

\section{Methodology}

The measurements of the principal research constructs were based on previous studies: those for social recognition, relationship proneness, and loyalty were adapted from the study of Odekerken-Schröder et al. [7]; those for need for variety and relational benefits were adapted from the study of Vázquez-Carrasco and Foxall [8]; those for social affiliation were adapted from the study of Cheek and Buss [15]; those for involvement were adapted from the study of Mittal [16]; those for satisfaction were adapted from the study of Kumar et al. [17]; and those for relationship commitment were adapted from the study of Morgan and Hunt [18].

After drafting a questionnaire, a person with a doctorate in Management Information Systems assessed the suitability of the items. Eight graduate students from the Department of Information Management who were online community members were then requested to answer the questionnaire. Consequently, ambiguous items were modified, ensuring that the respondents had complete understanding of the items. Finally, the questionnaire was pilot-tested on a small sample $(n=30)$, and the results showed that all constructs had $\alpha$ coefficients greater than 0.7 .

The subjects of the present study were online community members. A convenience sampling method was adopted; a link to the web-based questionnaire was posted on widely used online communities in Taiwan. In total, 629 questionnaires were returned, 599 of which were valid. The demographic characteristics of the respondents are presented in Table 1.
Table 1. Respondent profile.

\begin{tabular}{|c|c|c|c|}
\hline & & Nor values & $\%$ \\
\hline \multirow{2}{*}{ Gender } & Male & 330 & 55.1 \\
\hline & Female & 269 & 44.9 \\
\hline \multirow{4}{*}{ Age } & Min & 16 & \\
\hline & Max & 36 & \\
\hline & Mean & 23.85 & \\
\hline & S.D. & 3.14 & \\
\hline \multirow{4}{*}{$\begin{array}{l}\text { Disposable income } \\
\text { (NT\$) }\end{array}$} & Min & 0 & \\
\hline & Max & 150000 & \\
\hline & Mean & 12585.52 & \\
\hline & S.D. & 12687.1 & \\
\hline \multirow{4}{*}{ Education } & Junior high (or lower) & 4 & 0.7 \\
\hline & Senior high & 11 & 1.8 \\
\hline & Undergraduate & 427 & 71.3 \\
\hline & Graduate & 157 & 26.2 \\
\hline \multirow{4}{*}{$\begin{array}{l}\text { Experience of } \\
\text { participating in online } \\
\text { communities (years) }\end{array}$} & Min & 1 & \\
\hline & Max & 13 & \\
\hline & Mean & 4.63 & \\
\hline & S.D. & 2.50 & \\
\hline \multirow{10}{*}{$\begin{array}{l}\text { Types of most } \\
\text { frequently } \\
\text { participated online } \\
\text { communities }\end{array}$} & Business/Finance & 40 & 6.7 \\
\hline & Sports/race & 58 & 9.7 \\
\hline & Idol/star/celebrity & 28 & 4.7 \\
\hline & Friendship/chat & 60 & 10.0 \\
\hline & Academia/profession & 44 & 7.3 \\
\hline & Campus/club & 61 & 10.2 \\
\hline & Life/fashion & 80 & 13.4 \\
\hline & Game/entertainment & 92 & 15.4 \\
\hline & Shopping/transaction & 53 & 8.8 \\
\hline & Others & 83 & 13.9 \\
\hline
\end{tabular}

\section{Reliability and Validity}

This study used SmartPLS 2.0 [19] for the data analysis. First, a reliability analysis was performed; the results of which showed that the Cronbach's $\alpha$ of each construct exceeded the recommended value of 0.7 [20], except for that of involvement, which was 0.69 but still considered acceptable. In addition, the composite reliability of each construct was greater than 0.8 , indicating good reliability of the constructs [20]. The reliability statistics is presented in Table 2 .

Table 2. Reliability statistics.

\begin{tabular}{lll}
\hline Constructs & Cronbach's $\boldsymbol{\alpha}$ & Composite reliability \\
\hline Involvement (I) & 0.69 & 0.81 \\
Loyalty (L) & 0.79 & 0.86 \\
Need for variety (NV) & 0.80 & 0.87 \\
Relational benefits (RB) & 0.79 & 0.84 \\
Relationship commitment (RC) & 0.79 & 0.86 \\
Relationship proneness (RP) & 0.77 & 0.85 \\
Satisfaction (S) & 0.78 & 0.86 \\
Social affiliation (SA) & 0.72 & 0.83 \\
Social recognition (SR) & 0.70 & 0.81 \\
\hline
\end{tabular}

The outer loadings of the items for each construct were greater than 0.6, except for those of RB2 and SR4, which were then eliminated. Further analysis revealed that the outer loading of RB4 was less than 0.6. After RB4 was eliminated, the outer loadings of all remaining items were greater than 0.6 . The items with outer loadings less than 0.7 (i.e., I3, RB1, RB3, RB5, RB7, and RP4) were then eliminated. Reanalysis revealed that the outer loadings of the remaining items were all greater than 0.7 . The average variance extracted (AVE) of 
each construct was greater than 0.5 , demonstrating convergent validity [21]. Finally, the square root of the AVE for each construct was greater than its correlations with the other constructs, indicating considerable discriminant validity [21]. The validity statistics are presented in Tables 3 and 4 .

Table 3. Outer loadings.

\begin{tabular}{|c|c|c|}
\hline Construct codes (AVE) Item codes & Outer loadings & $t$-statistics \\
\hline \multicolumn{3}{|l|}{$\mathrm{I}(0.59)$} \\
\hline I1 & 0.80 & $21.55^{* *}$ \\
\hline I2 & 0.73 & $14.39 * *$ \\
\hline I4 & 0.76 & $18.18^{* *}$ \\
\hline \multicolumn{3}{|l|}{$\mathrm{L}(0.62)$} \\
\hline L1 & 0.71 & $14.21 * *$ \\
\hline L2 & 0.80 & $22.97 * *$ \\
\hline L3 & 0.87 & $43.14 * *$ \\
\hline L4 & 0.75 & $21.32 * *$ \\
\hline \multicolumn{3}{|l|}{$\mathrm{NV}(0.63)$} \\
\hline NV1 & 0.83 & $22.50 * *$ \\
\hline NV2 & 0.73 & $13.11 * *$ \\
\hline NV3 & 0.85 & $26.42 * *$ \\
\hline NV4 & 0.74 & $10.32 * *$ \\
\hline \multicolumn{3}{|l|}{ RB (0.74) } \\
\hline RB6 & 0.84 & $25.05^{* *}$ \\
\hline RB8 & 0.88 & $32.31 * *$ \\
\hline \multicolumn{3}{|l|}{$\mathrm{RC}(0.61)$} \\
\hline $\mathrm{RC} 1$ & 0.76 & $19.72 * *$ \\
\hline $\mathrm{RC} 2$ & 0.79 & $20.73 * *$ \\
\hline $\mathrm{RC} 3$ & 0.79 & $22.03 * *$ \\
\hline $\mathrm{RC} 4$ & 0.79 & $21.48 * *$ \\
\hline \multicolumn{3}{|l|}{$\mathrm{RP}(0.70)$} \\
\hline RP1 & 0.85 & $26.95 * *$ \\
\hline RP2 & 0.88 & $34.86^{* *}$ \\
\hline RP3 & 0.79 & $20.66 * *$ \\
\hline \multicolumn{3}{|l|}{$\mathrm{S}(0.61)$} \\
\hline S1 & 0.82 & $27.75^{* *}$ \\
\hline $\mathrm{S} 2$ & 0.78 & $19.72 * *$ \\
\hline $\mathrm{S} 3$ & 0.74 & $13.82 * *$ \\
\hline S4 & 0.78 & $22.46^{* *}$ \\
\hline \multicolumn{3}{|l|}{$\mathrm{SA}(0.55)$} \\
\hline SA1 & 0.75 & $17.32 * *$ \\
\hline SA2 & 0.78 & $19.78^{* *}$ \\
\hline SA3 & 0.70 & $11.96 * *$ \\
\hline SA4 & 0.73 & $15.35 * *$ \\
\hline \multicolumn{3}{|l|}{ SR (0.64) } \\
\hline SR1 & 0.79 & $19.13 * *$ \\
\hline SR2 & 0.78 & $14.79 * *$ \\
\hline SR3 & 0.81 & $17.43 * *$ \\
\hline
\end{tabular}

I: involvement; L: loyalty; NV: need for variety; RB: relational benefits; RC: relationship commitment; RP: relationship proneness; S: satisfaction; SA: social affiliation; SR: social recognition.

$* *: p<0.01$

Table 4. AVE and inter-construct correlations.

\begin{tabular}{|c|c|c|c|c|c|c|c|c|c|}
\hline \multirow{2}{*}{ Construct codes } & \multicolumn{9}{|c|}{ Correlations between constructs } \\
\hline & I & $\mathbf{L}$ & NV & RB & RC & $\mathbf{R P}$ & $\mathbf{S}$ & SA & SR \\
\hline I & 0.77 & & & & & & & & \\
\hline $\mathrm{L}$ & 0.47 & 0.79 & & & & & & & \\
\hline NV & 0.38 & 0.31 & 0.79 & & & & & & \\
\hline $\mathrm{RB}$ & 0.46 & 0.44 & 0.39 & 0.86 & & & & & \\
\hline $\mathrm{RC}$ & 0.48 & 0.67 & 0.30 & 0.46 & 0.78 & & & & \\
\hline $\mathrm{RP}$ & 0.63 & 0.54 & 0.33 & 0.51 & 0.55 & 0.84 & & & \\
\hline SA & 0.57 & 0.46 & 0.41 & 0.55 & 0.42 & 0.54 & 0.40 & 0.74 & \\
\hline SR & 0.43 & 0.38 & 0.40 & 0.45 & 0.33 & 0.43 & 0.33 & 0.57 & 0.80 \\
\hline
\end{tabular}

The main diagonal shows the square root of AVE.

I: involvement; L: loyalty; NV: need for variety; RB: relational benefits; RC: relationship commitment; RP: relationship proneness; S: satisfaction; SA: social affiliation; SR: social recognition. 


\section{Hypotheses Testing}

A bootstrapping algorithm was used with the resample size set to 500 to test the structural model. The path coefficients and model explanatory power are presented in Table 5 and Fig. 2, which show that $\mathrm{H} 2$ and $\mathrm{H} 4$ are not supported.

Table 5. Result of hypotheses testing.

\begin{tabular}{|c|c|c|c|c|c|}
\hline \multicolumn{2}{|c|}{ Hypotheses } & \multirow{2}{*}{$\begin{array}{l}\text { Path coefficients } \\
0.21\end{array}$} & \multicolumn{2}{|c|}{ t-values } & \multirow{2}{*}{$\begin{array}{l}\text { Supported? } \\
\text { Yes }\end{array}$} \\
\hline H1: & $\mathrm{SA} \rightarrow \mathrm{RP}$ & & 2.56 & * & \\
\hline $\mathrm{H} 2$ : & $\mathrm{SR} \rightarrow \mathrm{RP}$ & 0.12 & 1.58 & & No \\
\hline H3: & $\mathrm{I} \rightarrow \mathrm{RP}$ & 0.45 & 5.90 & $* *$ & Yes \\
\hline H4: & $\mathrm{NV} \rightarrow \mathrm{RP}$ & 0.03 & 0.50 & & No \\
\hline H5: & $\mathrm{RP} \rightarrow \mathrm{RB}$ & 0.52 & 8.10 & $* *$ & Yes \\
\hline H6: & $\mathrm{RB} \rightarrow \mathrm{S}$ & 0.49 & 7.55 & $* *$ & Yes \\
\hline H7: & $\mathrm{RB} \rightarrow \mathrm{RC}$ & 0.17 & 2.51 & $*$ & Yes \\
\hline H8: & $\mathrm{S} \rightarrow \mathrm{RC}$ & 0.60 & 8.56 & $* *$ & Yes \\
\hline H9: & $\mathrm{S} \rightarrow \mathrm{L}$ & 0.33 & 3.74 & $* *$ & Yes \\
\hline H10: & $\mathrm{RC} \rightarrow \mathrm{L}$ & 0.44 & 5.57 & $* *$ & Yes \\
\hline
\end{tabular}

$R^{2}: \mathrm{RP}=0.46 ; \mathrm{RB}=0.27 ; \mathrm{S}=0.24 ; \mathrm{RC}=0.49 ; \mathrm{L}=0.50$.

I: involvement; L: loyalty; NV: need for variety; RB: relational benefits; RC: relationship commitment; RP: relationship proneness; $\mathrm{S}$ : satisfaction; SA: social affiliation; SR: social recognition.

$*: p<0.05 ; * *: p<0.01$.

The results of structural model analysis confirmed positive effects of satisfaction $(\beta=0.33 ; p<0.01)$ and relationship commitment $(\beta=0.44 ; p<0.01)$ on loyalty, of satisfaction $(\beta=0.60 ; p<0.01)$ and relational benefits $(\beta=0.17 ; p<0.05)$ on relationship commitment, of relational benefits $(\beta=0.49$; $p<0.01)$ on satisfaction, of relationship proneness $(\beta=0.52$; $p<0.01)$ on relational benefits, and of social affiliation $(\beta=0.21$; $p<0.05)$ and involvement $(\beta=0.45 ; p<0.01)$ on relationship proneness. However, the effects of social recognition and need for variety on relationship proneness remained unconfirmed. The explained variances in relationship proneness, relational benefits, satisfaction, relationship commitment, and loyalty were $0.46,0.27,0.24,0.49$, and 0.50 , respectively.

\section{Discussion}

The theoretical contribution of this study is that the effects of personality traits on loyalty were examined in the context of online communities. This inclusion enabled exploring the role of individual differences in the formation of online loyalty. In addition, although previous research has focused primarily on the relationship between relationship proneness and satisfaction, the present study also examined the mediating role of relational benefits in the aforementioned relationship. This examination can elucidate the importance of relational benefits for relationship quality and loyalty.

The current findings indicated that both social affiliation and involvement are positively associated with relationship proneness. This suggests that people are prone to engage in a virtual relationship because they desire more social contact or because online communities fulfill their needs, interests, or values. However, the results of this study do not support the association of relationship proneness with social recognition and need for variety. A plausible explanation for this is that although online communities offer things of interest and a sense of belonging for members, they cannot provide the type of respect and recognition that members can experience in the real world. In addition, people with a higher need for variety likely demonstrate switch behavior [8]; therefore, they might not be particularly more involved in relationships that develop in the virtual world. Most previous studies have focused on the service industry in real-world settings and were conducted when online communities were not as prevalent as they are today. Hence, the current findings are inconsistent with those of previous studies.

Relationship proneness positively influences relational benefits, and relational benefits positively influence satisfaction and relationship commitment. This suggests that online community members with higher relationship proneness tend to perceive higher relational benefits, and in turn, they perceive higher relationship quality.

The current findings also indicate that satisfaction has a positive effect on relationship commitment and loyalty, and relationship commitment has a positive effect on loyalty. These findings accord with those documented in relationship marketing literature [22, 23, 24, 25]. In other words, the views of relationship marketing may be applicable to online communities.

Finally, this study suggests that online community operators must identify the needs and preferences of their members and provide facilitating tools to satisfy their members' needs for social contact and involvement. Consequently, their members will have higher relationship proneness, perceive higher relational benefits and quality, and further demonstrate higher loyalty to the community.
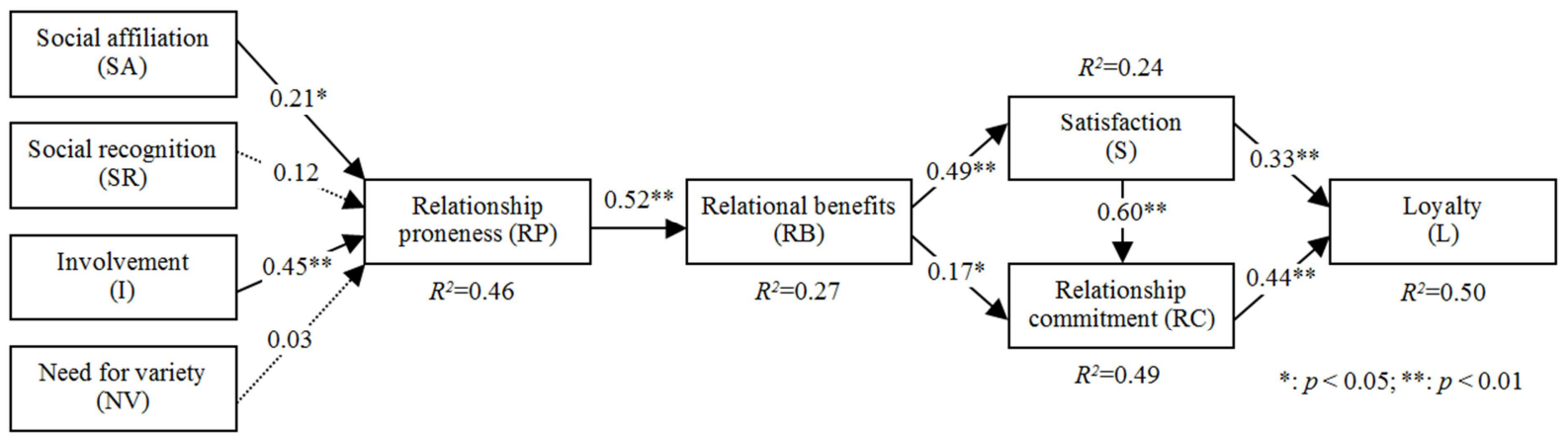

Figure 2. Path coefficients and R-squares. 


\section{Limitations and Suggestions}

The following are the limitations of this study: (1) The samples were collected from online communities in Taiwan; hence, further research will be required to generalize the study results to other cultures and countries. (2) The study was limited by time, budget, and human resources, and convenience sampling may have biased the results.

This study suggests the following for future studies: (1) Research should be conducted considering other personality straits. (2) Research should be conducted on various types of online communities and the differences should be compared. (3) This study regarded relational benefits as a unitary construct; future studies should be directed at specific benefit types. (4) This study represented relationship quality by using satisfaction and relationship commitment; future research should include constructs concerning trust.

\section{Conclusions}

This study examined the effects of personality traits on member loyalty to online communities. The results indicated that social affiliation and involvement exert influence on loyalty through the mediation of relationship proneness, relational benefits, and relationship quality. The perspectives of individuality and relationship marketing were proved to be useful in explaining the mechanism for building and maintaining loyalty in the context of online communities. The findings suggest that those participants who have a high level of social affiliation and involvement are more likely to exhibit loyal behavior and, accordingly, are the target of online community operators' campaigns for attracting new and retaining existing members.

\section{References}

[1] Hagel, J., \& Armstrong, A. (1997). Net Gain: Expanding Markets Through Virtual Communities. Boston, MA: Harvard Business School Press.

[2] Rheingold, H. (2000). The Virtual Community: Homesteading on the Electronic Frontier. Boston, MA: MIT press.

[3] Shih, Y.-W., Hsu, M.-H., \& Lee, D.-C. (2015). Self-disclosure, interpersonal relationships, and stickiness of online communities. Psychology and Behavioral Sciences, 4(2), 71-78.

[4] Rauyruen, P., \& Miller, K. E. (2007). Relationship quality as a predictor of B2B customer loyalty. Journal of Business Research, 60(1), 21-31.

[5] Hennig-Thurau, T., Gwinner, K. P., \& Gremler, D. D. (2002). Understanding relationship marketing outcomes: An integration of relational benefits and relationship quality. Journal of Service Research, 4(3), 230-247.

[6] De Wulf, K., Odekerken-Schröder, G., \& Iacobucci, D. (2001). Investments in Consumer Relationships: A Cross-Country and Cross-Industry Exploration. Journal of Marketing, 65(4), 33-50.
[7] Odekerken-Schröder, G., Wulf, K. D., \& Schumacher, P. (2003). Strengthening outcomes of retailer-consumer relationships: The dual impact of relationship marketing tactics and consumer personality. Journal of Business Research, 56(3), 177-190.

[8] Vázquez-Carrasco, R., \& Foxall, G. R. (2006). Influence of personality traits on satisfaction, perception of relational benefits, and loyalty in a personal service context. Journal of Retailing and Consumer Services, 13(3), 205-219.

[9] Adamson, I., Chan, K. M., \& Handford, D. (2003). Relationship marketing: customer commitment and trust as a strategy for the smaller Hong Kong corporate banking sector. International Journal of Bank Marketing, 21(6/7), 347-358.

[10] Park, C.-H., \& Kim, Y.-G. (2006). The effect of information satisfaction and relational benefit on consumers' online shopping site commitments. Journal of Electronic Commerce in Organizations, 4(1), 70-90.

[11] Caruana, A. (2004). The impact of switching costs on customer loyalty: A study among corporate customers of mobile telephony. Journal of Targeting, Measurement and Analysis for Marketing, 12(3), 256-268.

[12] Abdul-Muhmin, A. G. (2005). Instrumental and interpersonal determinants of relationship satisfaction and commitment in industrial markets. Journal of Business Research, 58(5), 619-628.

[13] Selnes, F. (1993). An examination of the effect of product performance on brand reputation, satisfaction and loyalty. European Journal of Marketing, 27(9), 19-35.

[14] Macintosh, G., \& Lockshin, L. S. (1997). Retail relationships and store loyalty: A multi-level perspective. International Journal of Research in Marketing, 14(5), 487-497.

[15] Cheek, J. M., \& Buss, A. H. (1981). Shyness and sociability. Journal of Personality and Social Psychology, 41(2), 330-339.

[16] Mittal, B. (1995). A comparative analysis of four scales of consumer involvement. Psychology and Marketing, 12(7), 663-682.

[17] Kumar, N., Stern, L. W., \& Achrol, R. S. (1992). Assessing reseller performance from the perspective of the supplier. Journal of marketing research, 29(2), 238-253.

[18] Morgan, R. M., \& Hunt, S. D. (1994). The commitment-trust theory of relationship marketing. The Journal of Marketing, 58(3), 20-38.

[19] Ringle, C. M., Wende, S., \& Will, A. (2005). SmartPLS (Version 2.0 beta). Available at http://www.smartpls.de

[20] Hair Jr., J. F., Anderson, R. E., Tatham, R. L., \& Black, W. C. (1995). Multivariate Data Analysis (3rd ed.). Englewood Cliffs, NJ: Prentice Hall.

[21] Fornell, C., \& Larcker, D. F. (1981). Evaluating structural equation models with unobservable variables and measurement error. Journal of Marketing Research, 18(1), 39-50.

[22] Hsiao, C.-H., Shen, G. C., \& Chao, P.-J. (2015). How does brand misconduct affect the brand-customer relationship? Journal of Business Research, 68(4), 862-866.

[23] Lee, D., Moon, J., Kim, Y. J., \& Yi, M. Y. (2015). Antecedents and consequences of mobile phone usability: Linking simplicity and interactivity to satisfaction, trust, and brand loyalty. Information \& Management, 52(3), 295-304. 
[24] Su, L., Swanson, S. R., Chinchanachokchai, S., Hsu, M. K., \& Chen, X. (2016). Reputation and intentions: The role of satisfaction, identification, and commitment. Journal of Business Research. In press.
[25] Yoo, C. W., Kim, Y. J., \& Sanders, G. L. (2015). The impact of interactivity of electronic word of mouth systems and E-Quality on decision support in the context of the e-marketplace. Information \& Management, 52(4), 496-505. 